\title{
Biochemical observations on rat aorta: interaction of dietary protein and cholesterol
}

\author{
BY S. P. BYDLOWSKI \\ Lipid Research Center, University Hospital, K-Pavilion, 4th Floor, Mail Location 540, \\ 234 Goodman Street, Cincinnati, Ohio 45267, USA \\ AND V. L. G. STIVALETTI AND C. R. DOUGLAS \\ Laboratorio de Medicina Experimental, Department of Physiological Sciences, \\ Faculdade de Ciencias Medicas da Santa casa de Sao Paulo, Sao Paulo, SP, Brazil
}

(Received 17 December 1984 - Accepted 8 November 1985)

\begin{abstract}
1. The effect of cholesterol feeding during and after a period of protein malnutrition lasting 4 weeks was examined in the rat. Indices measured were plasma total cholesterol, triglycerides and protein levels, and aorta total cholesterol, triglycerides, hexosamine and hydroxyproline concentrations.

2. In both plasma and aorta, total cholesterol and triglycerides levels were higher in the low-protein diet group than in the standard-protein diet group, when cholesterol was supplied in both diets.

3. During the malnutrition period, cholesterol feeding led to a greater decrease in plasma protein than that promoted by the low-protein diet without cholesterol, while aorta hexosamine levels decreased to a lesser extent.

4. Cholesterol feeding with a standard-protein diet promoted a slight and temporary increase in aorta hydroxyproline levels, while a decrease in aorta hexosamine concentration was observed. Cholesterol feeding with the low-protein diet, on the other hand, also promoted a decrease in aorta hexosamine levels but to a lesser extent.

5. During the recovery period, cholesterol feeding impaired the return of plasma protein, aorta hexosamine and lipid levels to that of the control values.

6. These findings demonstrate that cholesterol feeding promotes different changes in aorta and plasma, depending on whether or not protein is supplied by the diet in adequate amounts. This point could be important in relation to the development of atherosclerosis during recovery from a period of malnutrition.
\end{abstract}

Elevated plasma cholesterol concentration has been considered as one of the major risk factors for atherosclerosis development. The role of nutritional factors such as the types of dietary fat, carbohydrate and even mineral elements has been widely emphasized (Levy et al. 1979). Dietary protein has been recognized as another contributory factor in plasma and arterial wall lipid changes, even when normal energetic conditions were maintained (Bydlowski et al. 1981 $a, c$ ). The changes in arterial walls that occur under the influence of protein refeeding after a period on a low-protein diet, when plasma lipid levels are temporarily increased, has not been investigated to a great degree. It has been shown that there was a temporary increase in aorta lipid levels in this condition (Bydlowski et al. 1984). On the other hand, little is known about the influence of cholesterol feeding during the protein recovery period. To obtain more information about this, some of the lipid and protein constituents of the plasma and aorta from rats were studied during and after dietary protein restriction, and under the influence of dietary cholesterol supplementation.

\section{MATERIALS AND METHODS}

\section{Diets}

Two isoenergetic diets were used: a standard-protein diet $(276 \mathrm{~g}$ protein $/ \mathrm{kg})$ and a low-protein diet $(26 \mathrm{~g}$ protein $/ \mathrm{kg})$.

The composition of the standard-protein diet (Bydlowski et al. $1981 \mathrm{~b}$ ) was $(/ \mathrm{kg})$ : maize starch $290 \mathrm{~g}$, sucrose $100 \mathrm{~g}$, wheat flour $100 \mathrm{~g}$, soya-bean oil $120 \mathrm{~g}$, powdered milk $100 \mathrm{~g}$, 
casein $250 \mathrm{~g}$, brewer's yeast $30 \mathrm{~g}$, saline mixture of Osborne-Mendel $10 \mathrm{~g}$, retinol $6000 \mu \mathrm{g}$, cholecalciferol $50 \mu \mathrm{g}$, vitamin E $110 \mathrm{mg}$, vitamin K $50 \mathrm{mg}$, thiamin hydrochloride $21.9 \mathrm{mg}$, riboflavin $21.9 \mathrm{mg}$, calcium pantothenate $6.6 \mathrm{mg}$, biotin $0.44 \mathrm{mg}$, cyanocobalamin $0.03 \mathrm{mg}$, nicotinic acid $99 \mathrm{mg}$, pyridoxamine $21.9 \mathrm{mg}$, pteroylmonoglutamic acid $1.98 \mathrm{mg}$, myoinositol $109.9 \mathrm{mg}$, choline $1650 \mathrm{mg}, p$-aminobenzoic acid $110 \mathrm{mg}$.

The low-protein diet was casein-free and its protein content was derived only from the powdered milk. Equivalent energy was replaced by soya-bean oil and cellulose was added to increase the bulk. Although this low-protein diet contained about twice as much soya-bean oil as in the standard diet, it was considered to be a good experimental model to study the effects of varying levels of protein intake on arterial walls without changing plasma concentrations of total cholesterol, triglycerides and phospholipids (Bydlowski et al. 1981 b).

Cholesterol-containing diets had $20 \mathrm{~g}$ cholesterol added $/ \mathrm{kg}$.

\section{Design and analysis}

Male Sprague-Dawley rats (21-d-old), weighing 45-50 g, were used. Immediately after weaning, the rats were separated into the following groups: (a) the standard-protein group, which received the standard-protein diet for 4,6 and 8 weeks (groups $S_{4}, S_{6}$ and $S_{8}$ ); (b) the cholesterol group, which received the standard-protein diet with cholesterol for 4,6 and 8 weeks (groups $\mathrm{C}_{4}, \mathrm{C}_{6}$ and $\mathrm{C}_{8}$ ); (c) the low-protein group, which received the lowprotein diet for 4 weeks (group L); and (d) the low-protein high-cholesterol group, which received the low-protein diet with cholesterol for 4 weeks (group LC). At the end of the 4th week of treatment, some of the animals of group $\mathrm{L}$ were recovered by refeeding the standard-protein diet with or without cholesterol for 2 or 4 weeks (groups $L \rightarrow C_{2}, L \rightarrow C_{4}$, $\mathrm{L} \rightarrow \mathrm{S}_{2}$ and $\mathrm{L} \rightarrow \mathrm{S}_{4}$ ); some animals of group $\mathrm{LC}$, after the four treatment weeks, were also given the standard-protein diet with or without cholesterol for 2 or 4 weeks (groups $\mathrm{LC} \rightarrow \mathrm{C}_{2}, \mathrm{LC} \rightarrow \mathrm{C}_{4}, \mathrm{LC} \rightarrow \mathrm{S}_{2}$ and $\mathrm{LC} \rightarrow \mathrm{S}_{4}$ ).

Rats were allowed free access to food and water, weighed once weekly and kept on a $12 \mathrm{~h}$ light- $12 \mathrm{~h}$ dark cycle at $23^{\circ}$ room temperature.

At the end of each experimental period, rats were fasted for $16 \mathrm{~h}$ and then bled through the aorta under light diethyl ether anaesthesia. Plasma was separated by centrifugation and stored frozen until analysis. Total cholesterol (Rosenthal et al. 1957), triglycerides (Carlson, 1963) and total protein (Lowry et al. 1951) were determined in the plasma samples. After washing with cold $0.157 \mathrm{M}$-potassium chloride the aorta was cleaned mechanically and drawn. Collagen (Fitch et al. 1955) and lipids (Folch et al. 1957) were extracted. Total cholesterol (Rosenthal et al. 1957; Deykin \& Goodman, 1962), triglycerides (Carlson, 1963), hexosamine (Elson \& Morgan, 1933; Rimington, 1940), hydroxyproline (Newman \& Logan, 1950) and total protein (Lowry et al. 1951) were determined in the extraction solutions.

Statistical evaluation of results was performed using the Scheffe test after analysis of variance, $P<0.05$ being considered as statistically significant. Since the animals given the standard diet during 4-8 weeks showed no significant differences regarding the biochemical indices studied, all these animals were pooled into one single group (group $S$ ). As the biochemical values from animals at the beginning of the experiment $(21-\mathrm{d}$-old $)$ were similar to those from the control groups, they were not included.

\section{RESULTS}

Table 1 shows the body-weight changes (weight at the end of the experiment minus the weight at the beginning) of the rats of each group. The gain in weight of animals given the standard-protein diet was constant and was directly related to the length of the experimental period $\left(\mathrm{S}_{4}-\mathrm{S}_{8}\right)$, although the magnitude of the increase varied with each experimental period. 


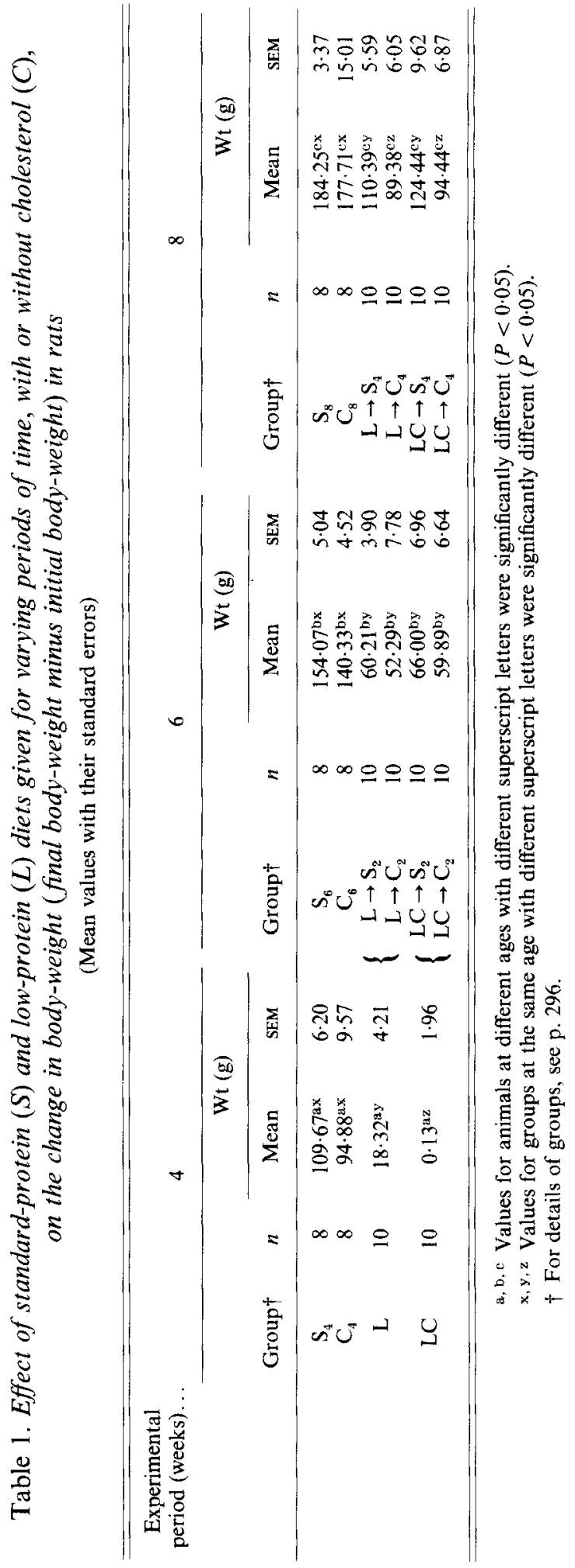


The same occurred with rats given the standard-protein cholesterol diet $\left(\mathrm{C}_{4}-\mathrm{C}_{8}\right)$. During cholesterol feeding, body-weights tended to be lower than those for rats fed on the standard-protein diet, but this was not significant. On the other hand, animals given the low-protein diet (L) showed a small increase in body-weight, while rats given the low-protein cholesterol diet (LC) did not exhibit a weight gain. This situation was reversed by refeeding the standard-protein diet, promoting an increase in body-weight which, by the end of the 4th week of recovery, reached the same value as that of rats from group $S_{4}\left(L \rightarrow S_{4}\right.$ and $\mathrm{LC} \rightarrow \mathrm{S}_{4} v . \mathrm{S}_{4} ; P>0.05$ ). Although the rats refed on the standard-protein cholesterol diet also showed an increase in body-weight, at the end of the 4th week of recovery these values were lower than those promoted by the refeeding of the standard-protein diet without cholesterol.

Table 2 shows the plasma levels of total cholesterol, triglycerides and total protein of rats given different diets. Plasma total cholesterol and triglycerides increased during cholesterol feeding, while plasma total protein decreased. These changes were not altered in magnitude by the time period (4-8 weeks) of cholesterol consumption. The low-protein diet (L) did not change total cholesterol and triglyceride in plasma, while it decreased plasma protein content. After this period, when malnourished rats were refed on the standard-protein diet for 2 weeks $\left(L \rightarrow S_{2}\right)$, there was an increase in plasma concentrations of total cholesterol and triglycerides. At the same time the plasma total protein content increased, but did not return to basal levels. The same was observed when rats were refed on the standard-protein cholesterol diet for 2 weeks $\left(\mathrm{L} \rightarrow \mathrm{C}_{2}\right.$ ), but under these conditions the increase in plasma lipid levels was more evident. After 4 weeks of protein refeeding $\left(L \rightarrow S_{4}\right)$, plasma total cholesterol and triglycerides decreased, returning to control values, while plasma total protein increased, reaching basal concentration during the same time. After 4 weeks of standard-protein cholesterol diet refeeding $\left(\mathrm{L} \rightarrow \mathrm{C}_{4}\right)$, plasma total cholesterol and triglycerides remained elevated while plasma protein increased slowly, without reaching control levels during this period. The low-protein cholesterol diet (LC) promoted an increase in plasma total cholesterol and triglycerides, while total protein content decreased significantly more than the levels observed in group $L(P<0.05)$. When these animals were refed on the standard-protein diet, plasma cholesterol and triglycerides decreased, reaching basal levels by the 4 th week of recovery $\left(\mathrm{LC} \rightarrow \mathrm{S}_{4}\right)$. This did not occur when the standard-protein diet was supplemented with cholesterol during the recovery period. All the measured lipids were maintained at high levels by the 4 th week $\left(\mathrm{LC} \rightarrow \mathrm{C}_{4}\right)$. In relation to total protein levels, cholesterol supplementation during recovery had no effect. These levels increased by similar magnitudes in both groups, without reaching control values even at the 4th week of recovery.

Table 3 shows the levels in the aorta of total cholesterol, triglycerides, hexosamine and hydroxyproline of rats given different diets. There was an increase in triglycerides and total cholesterol concentrations in the aortas of rats given the standard-protein cholesterol diet and the cholesterol levels increased relative to the time of experiment (4-8 weeks). Hydroxyproline content increased but was only significant in the 6th week of cholesterol consumption. The hexosamine levels decreased, with no relation to the experimental periods. Although the low-protein diet (L) promoted a decrease in total cholesterol, triglycerides, hexosamine and hydroxyproline in the aorta, only the decrease in hexosamine was significant. When these rats were refed on the standard-protein diet for 2 weeks $\left(\mathrm{L} \rightarrow \mathrm{S}_{2}\right)$, there was an increase in arterial wall content of total cholesterol and triglycerides which was greater than the control values. Hexosamine levels also increased but did not reach control levels, while hydroxyproline did not change. Total cholesterol and triglycerides returned to control values in the 4 th week of refeeding $\left(L \rightarrow S_{4}\right)$. The same was observed with hexosamine content while, surprisingly, hydroxyproline levels decreased. When 
Table 2. Plasma concentrations of total cholesterol, triglycerides and total protein of rats given standard-protein $(S)$ or low-protein $(L)$ diets with or without cholesterol $(C)$. Influence of dietary cholesterol on the recovery from a period of malnourishment

(Mean values with their standard errors)

\begin{tabular}{|c|c|c|c|c|c|c|c|}
\hline \multirow[b]{2}{*}{ Group $\dagger$} & \multirow[b]{2}{*}{$n$} & \multicolumn{2}{|c|}{$\begin{array}{c}\text { Total cholesterol } \\
(\mathrm{g} / \mathrm{l})\end{array}$} & \multicolumn{2}{|c|}{$\begin{array}{l}\text { Triglycerides } \\
(\mathrm{g} / 1)\end{array}$} & \multicolumn{2}{|c|}{$\begin{array}{c}\text { Total protein } \\
(\mathrm{g} / \mathrm{l})\end{array}$} \\
\hline & & Mean & SEM & Mean & SEM & Mean & SEM \\
\hline $\mathbf{S}$ & 24 & $0 \cdot 80$ & 0.03 & 0.93 & 0.04 & $72 \cdot 22$ & 0.53 \\
\hline $\mathrm{C}_{4}$ & 8 & $1 \cdot 60^{*}$ & $0 \cdot 18$ & $1 \cdot 60^{*}$ & 0.15 & $66.83^{*}$ & $1 \cdot 14$ \\
\hline $\mathrm{C}_{6}$ & 8 & $1 \cdot 54^{*}$ & 0.14 & $1.59^{*}$ & $0 \cdot 16$ & $65.94^{*}$ & 1.02 \\
\hline $\mathrm{C}_{8}$ & 8 & $1 \cdot 42^{*}$ & $0 \cdot 16$ & $1.43^{*}$ & 0.09 & $68 \cdot 54^{*}$ & 1.01 \\
\hline $\mathrm{L}$ & 10 & $0 \cdot 83^{\mathrm{a}}$ & 0.06 & $0.94^{\mathrm{a}}$ & 0.05 & $50 \cdot 27^{a *}$ & 0.82 \\
\hline $\mathrm{L} \rightarrow \mathrm{S}_{2}$ & 10 & $1.09^{\mathrm{b*}}$ & 0.05 & $1 \cdot 13^{\mathrm{b} *}$ & 0.08 & $61 \cdot 34^{b *}$ & 0.64 \\
\hline $\bar{L} \rightarrow \mathrm{C}_{2}$ & 10 & $1 \cdot 74^{\mathrm{c} *}$ & 0.12 & $1 \cdot 60^{\mathrm{c} *}$ & 0.18 & $59.93^{b *}$ & 1.53 \\
\hline $\mathrm{L} \rightarrow \mathrm{S}_{4}$ & 10 & $0.84^{2}$ & 0.06 & $0.93^{\mathrm{a}}$ & 0.02 & $71 \cdot 60^{\circ}$ & 0.94 \\
\hline $\mathrm{L} \rightarrow \mathrm{C}_{4}$ & 10 & $1 \cdot 46^{c *}$ & $0 \cdot 10$ & $1.47^{\mathrm{e} *}$ & 0.15 & $68 \cdot 81^{\mathrm{a} *}$ & 0.75 \\
\hline LC & 10 & $1 \cdot 26^{\mathrm{a} *}$ & 0.13 & $1.41^{\mathrm{a} *}$ & 0.17 & $47 \cdot 04^{a *}$ & 1.04 \\
\hline $\mathrm{LC} \rightarrow \mathrm{S}_{2}$ & 10 & $1 \cdot 35^{a *}$ & $0 \cdot 12$ & $1 \cdot 23^{a *}$ & 0.08 & $61 \cdot 83^{b *}$ & $1 \cdot 27$ \\
\hline $\mathrm{LC} \rightarrow \mathrm{C}_{2}$ & 10 & $1 \cdot 41^{a *}$ & 0.11 & $1 \cdot 35^{a *}$ & $0 \cdot 17$ & $61 \cdot 62^{\mathrm{b} *}$ & 1.01 \\
\hline $\mathrm{LC} \rightarrow \mathrm{S}_{4}$ & 10 & $0.88^{\mathrm{b}}$ & 0.06 & $0.94^{\mathrm{b}}$ & 0.08 & $64 \cdot 43^{\mathrm{c} *}$ & 1.03 \\
\hline $\mathrm{LC} \rightarrow \mathrm{C}_{4}$ & 10 & $1 \cdot 31^{a *}$ & 0.08 & $1 \cdot 25^{a *}$ & 0.07 & $66 \cdot 65^{\mathrm{c} *}$ & $1 \cdot 31$ \\
\hline
\end{tabular}

Significantly different from control values $(\mathrm{S}):{ }^{*} P<0 \cdot 05$.

a, b, e, d Comparison among different recovery diets from the same low-protein diet period (L or LC). Values with different superscript letters were significantly different $(P<0.05)$.

$\dagger$ For details of groups, see p. 296.

malnourished rats were refed on the standard-protein cholesterol diet for 2 weeks $\left(L \rightarrow C_{2}\right)$, cotal cholesterol, triglycerides and hexosamine contents in the aorta increased. By the 4th week of recovery $\left(\mathrm{L} \rightarrow \mathrm{C}_{4}\right)$, total cholesterol and triglycerides continued to increase while hydroxyproline maintained the same concentration, as observed before, and hexosamine reached control values. The low-protein cholesterol diet (LC) promoted an increase in total cholesterol and triglycerides concentrations in the aorta. Hydroxproline levels decreased but this was not significant, while hexosamine decreased to a lesser extent $(P<0.05)$ than that observed in group L. When LC rats were refed on the standard-protein diet, aorta total cholesterol and triglycerides decreased but only total cholesterol reached control values by the 4th week of recovery $\left(\mathrm{LC} \rightarrow \mathrm{S}_{4}\right)$. Hexosamine concentration increased and reached control levels also by the 4 th week, while hydroxyproline decreased significantly when compared with the control group. When LC rats were refed on the standard-protein cholesterol diet, aorta cholesterol content remained high during the recovery period. Triglycerides levels, although decreased, also remained high. The hydroxyproline concentration again decreased during cholesterol feeding when compared with control values. Hexosamine levels showed a slow increase when compared with the values observed by refeeding the standard-protein diet without cholesterol, and did not reach control levels.

\section{DISCUSSION}

Rats given the low-protein diet (L) had a poor general appearance. Their livers exhibited macroscopic signs of steatosis and increased hepatic weight in relation to body-weight compared with controls of the same age $(8.04$ (SE $0.37, n 10) v .4 .03(\mathrm{SE} 0.21, n 8) ; P<0.05)$. Also, their weight gain during this period was smaller than that of the controls. These 


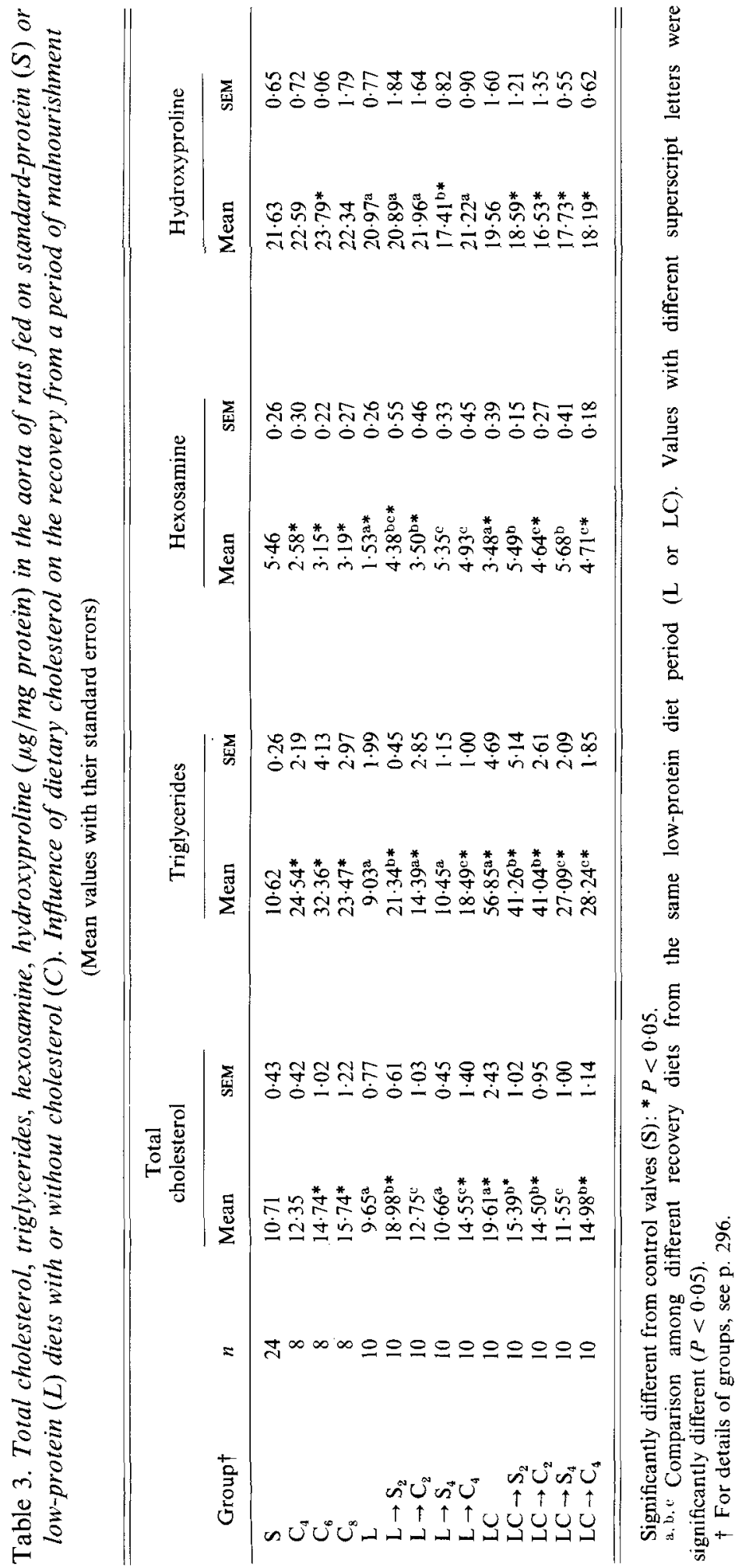


results, together with the low plasma total protein content, show that a severe degree of malnutrition was obtained. The malnutrition promoted by the low-protein cholesterol diet (LC) was of a greater magnitude. This could be concluded by the plasma total protein concentration, the body-weight gain, and by the liver weight:body-weight value (11.04 (SE 0.73), $n$ 10).

The standard-protein cholesterol diet produced an increase in plasma total cholesterol and triglycerides and a decrease in plasma protein content, probably due to decrease in hepatic protein synthesis promoted by cholesterol feeding (Saito \& Fillios, 1965). This diet also led to an incease in triglycerides and total cholesterol concentrations in the aorta. The hydroxyproline levels increased slightly temporarily while the hexosamine levels decreased. The changes in aorta triglycerides and hexosamine appeared by the 4th week of cholesterol feeding, while the changes in total cholesterol were progressive. This indicates that cholesterol was necessary for a longer period of time for these changes to be processed. These findings confirm previous published reports (Bydlowski et al. $1981 a, d$ ).

The effect of this low-protein diet on the studied biochemical indices in plasma and aorta have also been found in previous work, as well as the effect of the standard-protein diet given for 2 or 4 weeks following the low-protein diet period (Bydlowski et al. 1983, 1984). Although the low-protein diet promoted a decrease in plasma protein concentration, it appeared to have no significant effect on serum lipids. There seems to be considerable controversy regarding the effect of protein deficiency on serum lipid levels. Protein deficiency or dietary restriction was reported to decrease the levels of circulating cholesterol (Subbiah, 1977; Subbiah \& Siekert, 1979) without any effect on serum triglyceride concentration. Similar dietary treatment in chickens either had the opposite effect (Fisher et al. 1959), leading to higher levels of plasma cholesterol, or had no effect on the serum cholesterol level (Nikkila \& Ollila, 1957).

With regard to the changes that occurred in the arterial wall, Subbiah (1977) and Subbiah \& Siekert (1979) observed that there was a decrease in the total sterol content in the aorta of pigeons under conditions of protein deficiency or when the food supply was restricted. On the other hand, Little \& Angell (1977) have reported that pigeons given a low level of dietary protein did not present any significant change in the cholesterol concentration in the wall of the aorta. In the present report, rats given the low-protein diet showed no significant decrease of total cholesterol and triglycerides concentrations in arterial wall, which could reflect the results found in plasma. There was also a decrease in hexosamine levels observed in the aorta while hydroxyproline did not change.

Up to now, underlying reasons for the variable effects of dietary protein intake on plasma and arterial wall lipids have not been clearly established. It is possible that the contradictory findings among investigators are due to differences in animal species or to the composition of the diets used in the experiments, or even to the experimental time period. In the present experiment soya-bean oil was used as a source of energy instead of protein; the low-protein diet had therefore a high lipid content. It has been demonstrated that increasing the amount of soya-bean oil in the diet does not affect plasma cholesterol levels in rats (Wiggers et al. 1977) and also does not change the cholesterol content in the aorta of rabbits (Richard et al. 1982). Our findings confirm these results even when there was a lack of protein in the diet. Therefore, it is more likely that the observed effects in the aortic hexosamine levels are due to the lack of protein in the diet itself than to the increased content of soya-bean oil.

These alterations disappeared when the malnourished rats were refed on the standardprotein diet, as described previously (Bydlowski et al. 1984). The weight gain increased and, by the 4 th week of recovery $\left(\mathrm{L} \rightarrow \mathrm{S}_{4}\right)$, reached the same levels as those observed in group $\mathrm{S}_{4}$. After 2 weeks of protein restitution $\left(\mathrm{L} \rightarrow \mathrm{S}_{2}\right)$ an increase of total cholesterol and tri- 
glycerides in plasma was observed, perhaps due to a faster mobilization of lipids from the liver. This point of view is supported in part by the fact that at the end of the protein recovery period $\left(\mathrm{L} \rightarrow \mathrm{S}_{4}\right)$ there was a return of the previously high liver weight: body-weight value to control values $(3.92$ (SE $0.26, n 10)$ ). Also, the signs of previous fatty liver infiltration were clearly diminished. The increase in aorta total cholesterol and triglycerides observed in this period ( $\mathrm{L} \rightarrow \mathrm{S}_{2}$ ) could be due to the increased level of plasma lipids at the same time. Other factors may be considered since in the standard-protein cholesterol fed rats, the cholesterol level in the aorta increased more slowly, becoming significant only after 4 weeks $\left(\mathrm{C}_{4}\right)$ of cholesterol feeding. After 4 weeks of standard-protein refeeding after protein deprivation $\left(\mathrm{L} \rightarrow \mathrm{S}_{4}\right.$ ), plasma protein returned to basal levels while lipid levels were restored to control values in both plasma and arterial walls. Nevertheless, when arterial hexosamine content increased, returning toward control values, the hydroxyproline level decreased. The changes observed in hydroxyproline levels could be due to an increase in aorta total protein content (Bydlowski et al. 1984), possibly due to the low turnover of collagen in arteries.

When rats were recovered from the malnutrition period $(L)$ by using the standard-protein cholesterol diet, the increase of plasma total cholesterol and triglycerides was higher than that observed in groups recovered without cholesterol in the diet. These lipids remained at high levels until the conclusion of the experiment $\left(\mathrm{L} \rightarrow \mathrm{C}_{4}\right)$. At the same time plasma protein, although increased, remained at levels below those of the control, indicating that the plasma protein decreasing effect was promoted by cholesterol feeding. In aorta, total cholesterol and triglycerides levels increased slowly in relation to rats refed on the standardprotein diet alone. The underlying reason for this effect is not known. Aorta hexosamine levels increased during refeeding and, although the levels by the 4 th week of recovery $\left(\mathrm{L} \rightarrow \mathrm{C}_{4}\right.$ ) were lower than those of the controls, this difference was not significant. Aorta hydroxyproline did not change.

The low-protein cholesterol diet (LC) led to an increase of plasma total cholesterol and triglycerides levels. This effect cannot be attributed to an increase in cholesterol absorption (Corraze et al. 1984). It is probable that the lipid catabolism was affected, perhaps by liver impairment. The cholesterol added to the low-protein diet (LC) exacerbated the total protein decrease in plasma promoted by the low-protein diet without cholesterol (L) $(P<0.05)$, showing again that cholesterol feeding reduces plasma protein levels. In the aorta, this low-protein cholesterol-containing diet (LC) led to higher total cholesterol and triglycerides levels than those promoted by the standard-protein cholesterol diet in the same period of time $\left(\mathrm{C}_{4}\right)(P<0.05)$. Aorta hydroxyproline levels decreased in the LC group, although not significantly, while the decrease in aorta hexosamine concentration was less than that observed in group $\mathrm{L}(P<0.05)$. The effect of cholesterol added to the standard-protein diet when it promoted a decrease in hexosamine was greater than that observed when it was added to the low protein diet, in the same period of time $(P<0.05)$. Therefore, it appears that cholesterol feeding acts in different ways depending on whether or not protein is present in the diet in adequate amounts.

In the group of rats recovered from 4 weeks on the low-protein cholesterol diet the same conclusions can be drawn. Cholesterol feeding during recovery maintained high levels of plasma cholesterol and triglycerides, while rats given the cholesterol-free diet during the recovery period showed a return of these lipids to control values by the 4 th week $\left(\mathrm{LC} \rightarrow \mathrm{S}_{4}\right)$. Interestingly, the plasma total protein did not reach control values, unlike those in the $\mathrm{L} \rightarrow \mathrm{S}_{4}$ group, independently of the presence of cholesterol in the diet. Possibly, cholesterol feeding during the malnutrition period (LC) was responsible for this delayed effect. In the aorta, cholesterol feeding during recovery maintained the high levels of cholesterol $\left(\mathrm{LC} \rightarrow \mathrm{C}_{4}\right.$ ) while these levels returned to control values in the absence of cholesterol in the 
recovery diet $\left(\mathrm{LC} \rightarrow \mathrm{S}_{4}\right)$. Aorta triglycerides levels remained high, although slightly decreased, independent of the presence of cholesterol in the diet during the recovery period $\left(\mathrm{LC} \rightarrow \mathrm{S}_{4}\right.$ or $\mathrm{LC} \rightarrow \mathrm{C}_{4}$ ). This is probably due to the great amount of aorta triglycerides stored during the malnutrition period (LC).

Hexosamine levels in aorta increased during the recovery period, but reached control values only when cholesterol was not supplemented in the diet $\left(\mathrm{LC} \rightarrow \mathrm{S}_{4}\right)$. When rats were given cholesterol during this period, hexosamine did not reach control values $\left(\mathrm{LC} \rightarrow \mathrm{C}_{4}\right)$, indicating again the decreased effect of dietary cholesterol in aorta hexosamine levels. Interestingly, a decreasing effect of cholesterol feeding was seen on aorta hydroxyproline levels. Since, during the recovery period, cholesterol feeding increases aorta total protein (Bydlowski et al. 1984), different increasing rates between protein and hydroxyproline levels could explain the results. In other words, the increase in the aorta protein content during recovery was faster than the aorta hydroxyproline (Bydlowski et al. 1984), and this difference led to a relative decrease in the hydroxyproline levels. This also could explain the transitory effect of cholesterol $\left(\mathrm{C}_{6}\right)$ on the hydroxyproline levels, since it was also shown that dietary cholesterol increases aorta total protein levels (Bydlowski et al. 1981 a) faster than the hydroxyproline concentration.

In conclusion, the present study shows that cholesterol feeding promotes different changes in the studied biochemical indices in aorta and plasma, depending on whether or not protein was supplied by the diet in adequate amounts. If adequate protein is supplied, cholesterol feeding leads to an increase in plasma and aorta total cholesterol and triglycerides, a decrease in plasma protein and aorta hexosamine and tends to increase the aorta hydroxyproline. If protein is not present in adequate amounts in the diet, supplemental cholesterol feeding promotes a higher level of lipids in the plasma and in the aorta, a greater decrease in total protein in plasma and produces a smaller decrease in aorta hexosamine. Subsequent cholesterol addition during the recovery period interferes with the re-establishment of control values, at least during these experimental periods.

Further questions still remain. Is there, during the recovery of undernutrition in humans, a high atherogenesis? If so, what course of dietary treatment should be recommended for the recovery period from human undernutrition to prevent this kind of development?

The authors thank Dr M. T. R. Subbiah and R. L. Yunker for their helpful suggestions in the preparation of this manuscript.

\section{REFERENCES}

Bydlowski, S. P., Stivaletti, V. L. G. \& Douglas, C. R. (1981a). IRCS Medical Sciences 9, 743-744.

Bydlowski, S. P., Stivaletti, V. L. G. \& Douglas, C. R. (1981 b). IRCS Medical Sciences 9, 834.

Bydlowski, S. P., Stivaletti, V. L. G. \& Douglas, C. R. (1981 c). IRCS Medical Sciences 9, 895.

Bydlowski, S. P., Stivaletti, V. L. G. \& Douglas C. R. (1981d). In Advances of Physiological Sciences, vol. 5, pp. 185-192 [M. Palkovic, editor]. New York: Pergamon Press.

Bydlowski, S. P., Stivaletti, V.L. G. \& Douglas, C. R. (1983). IRCS Medical Sciences 11, $298-299$.

Bydlowski, S. P., Stivaletti, V. L. G. \& Douglas, C. R (1984). Annals of Nutrition and Metabolism 28, 85-91.

Carlson, L. A. (1963). Journal of Atherosclerosis Research 3, 334-336.

Corraze, G., Lacombe, C. \& Nibbelink, M. (1984). Lipids 19, 812-814.

Deykin, D. \& Goodman, D. S. (1962). Journal of Biological Chemistry 237, 3649-3651.

EIson, L. A. \& Morgan, W. T. J. (1933). Biochemistry 27, 1824-1828.

Fisher, H., Feigenbaum, A., Leveille, G. A., Weiss, H. S. \& Griminger, P. (1959). Journal of Nutrition 69, $163-171$.

Fitch, S. M., Harkness, M. L. R. \& Harkness, R. D. (1955). Nature 176, 163.

Folch, J., Lees, M. \& Stanley, G. H. S. (1957). Journal of Biological Chemistry 226, 497-509.

Levy, R., Rifkind, B., Dennis, B. \& Ernst, N. (1979). Nutrition, Lipids and Coronary Heart Disease. New York:

Raven Press.

Little, J. M. \& Angell, E. A. (1977). Atherosclerosis 26, 173-179. 


\section{S. P. Bydlowski, V. L. G. Stivaletti and C. R. Douglas}

Lowry, O. H., Rosebrough, N. J., Farr, A. L. \& Randail, R. J. (1951). Journal of Biological Chemistry 193, 265-275.

Newman, R. E. \& Logan, M. A. (1950). Journal of Biological Chemistry 184, 299-306.

Nikkila, E. A. \& Ollila, O. (1957). Acta Pathologica Microbiologica Scandinavica 40, 177-180.

Richard, M. J., Serbus, D. C., Beitz, D. C. \& Jacobson, N. L. (1982). Nutrition Research 2, 175-183.

Rimington, C. (1940). Biochemical Journal 34, 931-940.

Rosenthal, H. L., Pfluke, B. S. M. L. \& Buscaglia, S. (1957). Journal of Laboratory and Clinical Medicine 50. 318-322.

Saito, S. \& Fillios, L. C. (1965). American Joumal of Physiology 208, 882-886.

Subbiah, M. T. R. (1977). Nutrition Reports International 15, 223-229.

Subbiah, M. T. R. \& Siekert, R. G. Jr (1979). British Journal of Nutrition 41, 1-6.

Wiggers, K. D., Richard, M. J., Stewart, J. W., Jacobson, N. L. \& Berger, P. J. (1977). Atherosclerosis 27, $27-34$. 